\title{
Cell adhesion molecules in Alzheimer's disease
}

This article was published in the following Dove Press journal:

Degenerative Neurological and Neuromuscular Disease

4 July 2012

Number of times this article has been viewed

\section{Malin Wennström Henrietta M Nielsen \\ Department of Clinical Sciences Malmö, Lund University, Malmö, Sweden}

Correspondence: Henrietta M Nielsen Molecular Memory Research Unit, Department of Clinical Sciences Malmö, Lund University, The Wallenberg Laboratory 2nd Floor, Skåne University Hospital Malmö, 20502 Malmö, Sweden Tel +4640335733

Fax +46 4033704

Email henrietta.nielsen@med.lu.se
Abstract: Cell adhesion molecules (CAMs) mediate interactions between cells and their surroundings that are vital to processes controlling for cell survival, activation, migration, and plasticity. However, increasing evidence suggests that CAMs also mediate mechanisms involved in several neurological diseases. This article reviews the current knowledge on the role of CAMs in amyloid- $\beta$ (A $\beta$ ) metabolism, cell plasticity, neuroinflammation, and vascular changes, all of which are considered central to the pathogenesis and progression of Alzheimer's disease (AD). This paper also outlines the possible roles of CAMs in current and novel AD treatment strategies.

Keywords: cell adhesion molecules, Alzheimer's disease, neuroinflammation, plasticity, amyloid-beta, vascular changes

\section{Introduction}

Interactions between cells and the surrounding extracellular matrix (ECM) are crucial to processes controlling for cell proliferation, activation, migration, and survival. These interactions are dependent on specific adhesion processes that are orchestrated by a group of molecules referred to as cell adhesion molecules (CAMs). CAMs are transmembrane proteins with a cytoplasmic tail. Based on their specific molecular structures, they are generally classified into four major CAM families: selectins, integrins, immunoglobulin (Ig)-like CAMs (Ig-CAMs), and cadherins (schematically illustrated in Figure 1). These CAM families can be further divided into subfamilies (see Table 1).

The selectin family consists of three known members that mediate the initial steps of the leukocyte adhesion cascade, ${ }^{1}$ the lymphocyte homing receptor (L-selectin), the endothelial leukocyte adhesion molecule (E-selectin), and the platelet-activationdependent granule-external protein (P-selectin). All selectins interact with sialylated glycans in $\mathrm{Ca}^{2+}$-dependent manner. As implicated by their names, L-selectin is primarily expressed by leukocytes, E-selectin by activated endothelial cells, and P-selectin by platelets and endothelial cells. ${ }^{2}$ Soluble forms of all three selectins can be found in both plasma and in cerebrospinal fluid (CSF) ${ }^{3-6}$ and appear to reflect the activation state of the originating cells.

Integrins belong to a family that includes 18 alpha and 9 beta subunits. ${ }^{7}$ The subunits form at least 24 different heterodimeric receptors, and through these receptors, cells communicate with the ECM and surrounding cells, both outside-in and inside-out. ${ }^{8}$ When the ECM or CAMs expressed on neighboring cells adhere to 


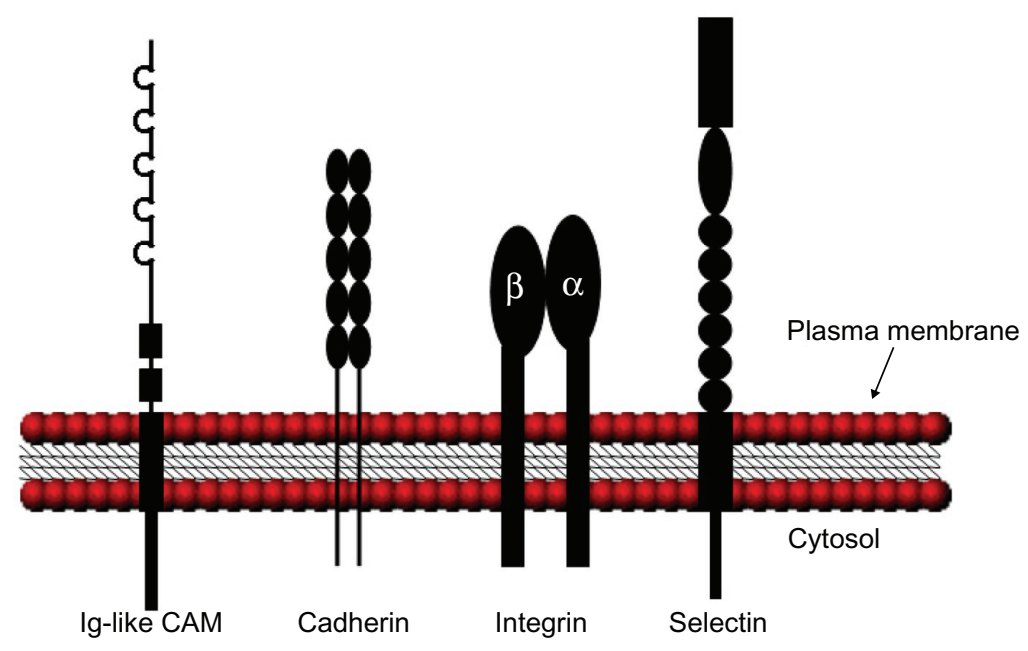

Figure I Schematic illustration of the various CAM structures. Ig-like CAMs are defined by one or more extracellular Ig repeats of 60 to 100 amino acids that form the active adhesion site and a transmembrane segment with a cytoplasmic tail. Classical cadherins have five extracellular cadherin repeats, a single transmembrane domain, and an intracellular tail. Integrin heterodimeric receptors are formed by $\alpha$ and $\beta$ transmembrane units. Selectins have a short cytoplasmic carboxyl terminus, a transmembrane sequence followed by complement regulatory-like molecules, and an extracellular component containing an epidermal growth factor-like domain and an amino terminal domain that is homologous to C-type lectins. Adapted with permission from Marchetti PJ, O'Connor P. Cellular adhesion molecules in neurology. Can J Neurol Sci. 1997;24(3):201."

Abbreviations: CAM, cell adhesion molecule; Ig, immunoglobulin.

integrins, recruitment of cytosolic non-receptor tyrosine kinases (NRTK) and cytoskeleton proteins (CSK) occur and form focal adhesion complexes (FAC). These complexes associate with the actin cytoskeleton and multiple signaling pathways that involve processes such as cell survival, inflammation, and angiogenesis, while synaptic transmission becomes efficiently regulated. ${ }^{9}$ Integrins are found on most cells throughout the brain and are region-specific as well as cell-type-specific. ${ }^{9}$ In addition, some integrins are known to actively shed from the cell surface in response to environmental changes such as inflammation. ${ }^{10}$

The Ig-CAMs are defined by one or more Ig repeats of 60 to 100 amino acids forming the active adhesion site. CAMs in this family can be found both in the periphery, where Ig-CAM mediated interactions are mostly heterophilic, and in the nervous system, where interactions are predominantly homophilic. ${ }^{11}$ Several Ig-CAM members appear to be specific to nervous tissue ${ }^{12,13}$ where they play vital roles in, for example, neurogenesis, neurite elongation, and brain plasticity. Furthermore, Ig-CAMs can be shed from cell membranes ${ }^{14}$ and the soluble versions may have separate effects from the cell-bound forms. ${ }^{15}$

Cadherins, particularly the classical cadherin and protocadherin subfamilies, are found throughout the nervous system. The two cadherin subfamilies are found mostly on neuronal synapses ${ }^{16,17}$ and extensive studies have shown that classical cadherins play a crucial role in neuronal plasticity and synaptogenesis. ${ }^{17}$ The functions of classical cadherins are mediated by a complex that is formed between the cytoplasmic tail of the cadherin and the cytosolic catenins, which are linked to the actin cytoskeleton. ${ }^{17}$ Like the other CAMs, cadherins are sensitive to proteolytic shedding. ${ }^{18}$

Collectively, CAMs orchestrate important functions in many vital physiological processes. However, increasing evidence suggests that CAMs are involved in the pathophysiology of several neurological diseases. This review summarizes current knowledge on the role of CAMs in events considered central to the pathogenesis and progression of Alzheimer's disease $(\mathrm{AD})$ such as amyloid- $\beta(\mathrm{A} \beta)$ metabolism, neuronal plasticity, inflammation, and vascular changes (data summarized in Table 2). We also discuss the potential impact of the involvement of CAMs in these processes in terms of cognitive symptoms in $\mathrm{AD}$ patients. Finally, this paper reviews current $\mathrm{AD}$ treatment strategies and the possible use of CAMs as targets in current and future $\mathrm{AD}$ treatments.

\section{Alzheimer's disease pathogenesis}

Neuropathologically, AD is primarily characterized by intraneuronal neurofibrillary tangles (NFTs) of hyperphosphorylated tau and extracellular deposits of mainly aggregated $\mathrm{A} \beta$ peptide, known as senile or neuritic plaques. ${ }^{19}$ According to the amyloid cascade hypothesis, the aggregation and deposition of $A \beta$ in brain tissue is key to $A D$ pathogenesis with the formation of tau pathology, inflammatory processes, and neurodegeneration as downstream events. ${ }^{20}$ The $A \beta$ peptide is generated by proteolytic processing of the amyloid precursor protein (APP) via sequential cleavage by the 
Table I Representative CAMs and expression distribution

\begin{tabular}{ll}
\hline CAMs & Expression distribution \\
\hline $\begin{array}{l}\text { Selectins } \\
\text { E-selectin }\end{array}$ & Endothelium, activated astrocytes \\
P-selectin & Endothelium, platelets \\
L-selectin & Leukocytes \\
Integrins & \\
$\alpha 5 \beta$ I & B- and T-cells, astrocytes, endothelium \\
$\alpha I \beta$ I & Astrocytes, endothelium \\
$\alpha 6 \beta$ I & T-cells, microglia, oligodendroglia \\
& endothelium \\
$\alpha v \beta 3$ & B- and T-cells, monocytes, endothelium, \\
& microglia, oligodendroglia \\
$\alpha L \beta 2$ & Leukocytes, macrophages, T-cells, \\
& microglia \\
$\alpha M \beta 2$ & B-cells, NK-cells, macrophages, microglia \\
$\alpha X \beta 2$ & Dendritic cells, B-cells, macrophages, \\
& microglia \\
Immunoglobulin superfamily \\
ICAM-I & Endothelium, astrocytes, microglia \\
NCAM & Neurons \\
VCAM-I & Endothelium, monocytes \\
PECAM-I & Endothelium, leukocytes \\
L1CAM & Neurons \\
Cadherins & \\
Classical cadherins & Neurons \\
N-cadherin & Endothelium, neurons \\
E-cadherin & \\
Protocadherins & Neurons \\
Clustered & Nonclustered
\end{tabular}

Abbreviations: CAM, cell adhesion molecule; E-cadherin, epithelial cadherin; E-selectin, endothelial leukocyte cell adhesion molecule; ICAM-I, intercellular cell adhesion molecule I; L1CAM, L1 cell adhesion molecule; L-selectin, leukocyte selectin; $\mathrm{N}$-cadherin, neuronal cadherin; NCAM, neural cell adhesion molecule; PECAM-I, platelet endothelial cell adhesion molecule I; P-selectin, platelet-activation-dependent granule-external protein; VCAM-I, vascular cell adhesion molecule I.

enzymes $\beta$-secretase 1 (BACE 1 ) and $\gamma$-secretase of which the latter is a complex consisting of presenilin 1 (PSEN1), presenilin 2 (PSEN2), and nicastrin. ${ }^{21}$ Genetic evidence links mutations of the genes encoding PSEN1 and PSEN2 to the familial early onset form of $\mathrm{AD}(\mathrm{EOAD}) .^{22}$ Furthermore, the presence of the $\varepsilon 4$ allele of apolipoprotein E (APOE) - the most well described genetic risk factor for sporadic AD, known as late onset $\mathrm{AD}(\mathrm{LOAD})^{23}$ - was shown to promote $\mathrm{A} \beta$ fibrillogenesis, deposition, and plaque formation. ${ }^{24}$ Therefore, imbalanced $A \beta$ metabolism with increased $A \beta$ production and insufficiently augmented $A \beta$ clearance in $\mathrm{EOAD}$, as well as normal $\mathrm{A} \beta$ production, but defective $\mathrm{A} \beta$ clearance in LOAD, are believed to be central events in the development of AD.

Next to the core pathological events of $A \beta$ deposition and intraneuronal tau accumulation, the presence of inflammatory processes, mainly driven by glial cells, are well described findings in the brains of patients with $\mathrm{AD} .^{25}$ Numerous studies have demonstrated increased levels of inflammatory markers in the brain tissue as well as in the CSF and plasma of AD patients, ${ }^{26,27}$ and epidemiological studies have suggested that non-steroidal anti-inflammatory treatment may reduce the risk and slow down the progression of $\mathrm{AD} .{ }^{25} \mathrm{Also}$, neurovascular alterations and white matter lesions reflecting cerebrovascular pathology as well as blood brain barrier (BBB) alterations have frequently been described in dementia disorders such as AD. ${ }^{28}$ Vascular pathology has even been proposed as a causal or contributing factor in at least $50 \%$ of all dementia cases. ${ }^{29}$ Importantly, most AD patients are affected by the vascular deposition of $A \beta$, cerebral amyloid angiopathy (CAA). ${ }^{30}$

The alteration of the glutamatergic and cholinergic systems are other well-described AD features. The glutamateric aberration, including glutamate excitotoxicity mediated through glutamate receptors such as N-methyl-D-aspartate receptors (NMDARs), can either be caused by an $\mathrm{A} \beta$-induced increase in glutamate release or a decrease in glutamate uptake. Furthermore, the loss of cholinergic neurons and various subtypes of acetylcholine receptors are hallmarks of $\mathrm{AD}$, and may interfere with the cholinergic mechanisms that contribute to glutamatergic transmission and synapse plasticity. Together, these alterations may contribute to a decline in cognitive functions. ${ }^{31-33}$

Not all of the described pathological events can be directly linked to the cognitive deterioration associated with $\mathrm{AD}$, which causes uncertainty surrounding the potential causal roles of these events. Approximately one-third of cognitively normal elderly subjects display some degree of AD pathology and many of these individuals would fulfill the criteria for postmortem $\mathrm{AD}$ diagnoses despite the absence of cognitive symptoms. Attempts to elucidate the correlation between postmortem findings and clinical symptoms displayed a better correlation between neurofibrillary tau pathology, rather than amyloid pathology, and cognitive impairment. ${ }^{34,35}$ However, the best morphological correlate of cognitive dysfunction in clinical AD appears to be loss of synapses ${ }^{36,37}$ with synaptic injury developing early in $\mathrm{AD}$ pathogenesis. ${ }^{38,39}$

Taken together, the current understanding supports the notion that $\mathrm{AD}$ results from a series of slowly developing neuropathological changes with a long asymptomatic phase preceding cognitive impairment. Therefore, early treatment strategies may prove to be the most efficient mode of prevention. 
Table 2 CAMs linked to AD pathological events

\begin{tabular}{|c|c|c|}
\hline Cell adhesion molecule & Mechanism & Reference \\
\hline \multicolumn{3}{|l|}{ Neuronal plasticity } \\
\hline \multirow[t]{2}{*}{ NCAM } & Increased expression in hippocampus of AD brain, decreased expression & $43-46$ \\
\hline & in frontal/temporal cortex of $A D$ brain, tendency to increased CSF levels in $A D$ patients & \\
\hline LICAM & Increased in CSF from AD patients & 49 \\
\hline N-cadherin & $\begin{array}{l}\text { Cleavage inhibited and upregulated/downregulated in response to } A \beta \text { in vivo, } \\
\text { synapse stabilization dependent on presenilin cleavage }\end{array}$ & $18,52-54,56,57,59,60$ \\
\hline Integrin unit $\alpha v$ & Mediate $A \beta$-induced LTP inhibition & 61 \\
\hline \multicolumn{3}{|l|}{$A \beta$ metabolism } \\
\hline Integrin unit $\alpha 4$ & Increased in aged brain, found adjacent to plaques & 62 \\
\hline Integrin unit $\beta 3$ & Found adjacent to plaque and tangles & 63 \\
\hline$\alpha 5 \beta$ I & Involved in degradation of $A \beta$ in vitro & 67 \\
\hline Integrin/FAK & Involved in modulation of $A \beta$ neurotoxicity & 65 \\
\hline$\alpha|\beta|$ & Downregulated by $A \beta$ in vitro, rescued by estradiol & 66 \\
\hline N-cadherin & Increased APP dimerization, $A \beta$ release, decrease $A \beta 42 / 40$ ratio & $70,7 \mid$ \\
\hline E-cadherin & Promote APP derivate, inhibit $A \beta$ production & 75 \\
\hline Integrin unit $\beta$ | & Mediate microglial internalization of fibrillar $A \beta$ & 68 \\
\hline \multicolumn{3}{|l|}{ Immunological events } \\
\hline ICAM-I & $\begin{array}{l}\text { Upregulated in response to } A \beta \text { in vitro, increased plasma levels in } A D \text { patients, } \\
\text { increased expression in } A \beta \text { plaque, identified in plaque, correlated with } \\
\text { hyaluronic acid in female } A D\end{array}$ & $84,90,92-96$ \\
\hline VCAM-I & $\begin{array}{l}\text { Upregulated in response to } A \beta \text { in vitro, increased plasma levels in } A D \text { patients, } \\
\text { decreased CSF levels in AD patients, }\end{array}$ & $84,92,93$ \\
\hline PECAM-I & $\begin{array}{l}\text { Involved in } A \beta \text {-induced transendothelial migration of monocytes, increased } \\
\text { plasma levels in } A D \text { patients }\end{array}$ & 84,92 \\
\hline$\alpha 6 \beta$ I & Mediate fibrillar $A \beta$ induced microglial activation & 100 \\
\hline$\alpha v \beta 3 / 5$ & Mediate neuronal phagocytic signal to microglial & 101 \\
\hline$\alpha \mathrm{L} \beta 2$ & Increased expression in AD brain & 143 \\
\hline$\alpha M \beta 2$ & Increased expression in $A D$ brain, mediate $A \beta$ induced neuroinflammation & 103,143 \\
\hline$\alpha \times \beta 2$ & Increased expression in AD brain & 143 \\
\hline \multicolumn{3}{|l|}{ Vascular changes } \\
\hline E-selectin & Increased in plasma of $A D$ patients with vascular changes & 93,108 \\
\hline P-selectin & Increased in plasma of $A D$ patients with fast cognitive decline & \\
\hline$\alpha v \beta 3$ & Increased in angiogeneic vessels in $A D$ brain & 114 \\
\hline
\end{tabular}

Abbreviations: $A \beta$, amyloid- $\beta$; AD, Alzheimer's disease; APP, amyloid precursor protein; CAM, cell adhesion molecule; CSF, cerebrospinal fluid; E-cadherin, epithelial cadherin; E-selectin, endothelial leukocyte cell adhesion molecule; FAK, focal adhesion kinase; ICAM-I, intercellular cell adhesion molecule I; L1CAM, L1 cell adhesion molecule; LTP, long-term potentiation; N-cadherin, neuronal cadherin; NCAM, neural cell adhesion molecule; PECAM-I, platelet endothelial cell adhesion molecule I; P-selectin, platelet-activation-dependent granule-external protein; VCAM-I, vascular cell adhesion molecule I.

\section{CAMs in altered synaptic and neuronal plasticity}

The neurodegeneration and subsequent massive neuron loss associated with $\mathrm{AD}$ is considered to be paralleled by altered neurogenesis, which may be induced by A $\beta$-related mechanisms. ${ }^{40}$ In the adult brain, neurogenesis has been identified in the hippocampus and the subventricular zone (SVZ). ${ }^{41,42}$ Expression of the neural cell adhesion molecule (NCAM), especially the highly polysialylated NCAM (PSA-NCAM) is considered an indicator of neurogenesis, neuronal remodeling, and plasticity, and has therefore been evaluated in AD brains. Results obtained by the use of immunohistochemistry and enzyme-linked immunosorbent assay (ELISA) suggest that alteration in NCAM expression in AD patients is brain-area dependent. Expression of hippocampal PSA-NCAM in AD patients was shown to increase with disease severity, ${ }^{43,44}$ whereas fewer NCAM positive neurons as well as lower NCAM expression were found in the frontal and temporal cortex of AD patients versus normal aging controls. ${ }^{45,46}$ The physiological roles of the soluble forms of NCAM are not completely elucidated but may implicate longterm potentiation (LTP), which is a cellular model of learning and memory. ${ }^{47}$ In a small study on Parkinson's disease and $\mathrm{AD}$ patients, the latter displayed increased CSF levels of the soluble NCAM-120 splice variant compared to the controls. ${ }^{48}$ Similarly, another study demonstrated a tendency towards elevated levels of soluble NCAM in the CSF of AD patients versus the controls. ${ }^{49}$ The latter study also showed that CSF 
concentrations of the L1 cell adhesion molecule (L1CAM), postulated to be involved in neurite elongation, fasciculation, and migration ${ }^{50}$ increased by $48 \%$ in $\mathrm{AD}$ patients versus the controls. ${ }^{49}$ The significance of these findings and the impact of altered NCAM and L1 expression on cognitive performance require further investigation.

As mentioned previously, synapse loss is strongly correlated with cognitive decline in AD patients. ${ }^{37}$ Since cadherins, particularly neuronal cadherins (N-cadherins), are important for synaptic formation and stability, ${ }^{51}$ they have become interesting research targets for their possible role in $\mathrm{AD}$ pathology and clinical disease manifestations. Studies of mice cortically injected with $\mathrm{A} \beta$ showed that the pedptide inhibited cleavage, ${ }^{52}$ but increased the expression, of $\mathrm{N}$-cadherin. ${ }^{53}$ In contrast, a study on murine primary neurons showed that $A \beta 42$ exposure decreased $N$-cadherin expression through the glutamate N-Methyl-D-aspartate (NMDA) receptors and that the $\mathrm{N}$-cadherin downregulation was followed by phosphorylation of the p38 mitogen activation protein kinase (p38 MAPK) and tau. Therefore, the decreased N-cadherin expression may be linked to tau pathology and, ultimately, to cognitive malperformance. ${ }^{54}$ The activation of p38 MAPK is noteworthy since it is an intracellular transduction factor that becomes activated by oxidative stress and cytokine secretion, ${ }^{55}$ both of which are processes linked to AD pathology.

As previously mentioned, mutations in the genes encoding for the presenilins, foremost known as the catalytic component of the $\mathrm{A} \beta$ generating $\gamma$-secretase, are linked to EOAD. ${ }^{21}$ However, presenilin is also recruited to the synaptic adhesion site, where it binds to the cadherin-catenin complex and, in response to membrane depolarization or NMDAR stimulation, cleaves N-cadherin. ${ }^{18}$ Support for its proteolytic effect on N-cadherin is found in functional studies showing a complete loss of $\mathrm{N}$-cadherin cleavage caused by mutations in the PSEN1 gene. ${ }^{56}$ The cleavage of $\mathrm{N}$-cadherin was also proven to generate a cytosolic protein fragment, termed the carboxy-terminal fragment of $\mathrm{N}$-cadherin (N-Cad/CTF2). This fragment was also shown to disturb the interaction between cyclic adenosine monophosphate (cAMP), response element-binding (CREB), and CREB binding protein (CBP), ${ }^{57}$ a complex that is critical to several processes affected by $A D$, such as synaptic plasticity and memory. ${ }^{58}$ Interestingly, recruitment of presenilin to the cadherin-catenin complex occurs at the expense of the presenilin $/ \gamma$-secretase cleavage of APP, ${ }^{59}$ which inhibits the amyloidogenic pathway. Finally, presenilin may also play a role in the trafficking of N-cadherin since cells that express mutant presenilin express less $\mathrm{N}$-cadherin ${ }^{60}$ which, as previously mentioned, may lead to tau phosphorylation. ${ }^{54}$

Numerous studies have shown that integrins are also involved in synaptic transmission, synaptic plasticity, and LTP. $^{9}$ Therefore, it is interesting that a preclinical study demonstrated the preventative role of integrin $\alpha \mathrm{v}$ on $\mathrm{A} \beta$-induced LTP inhibition, ${ }^{61}$ which when extrapolated, may counteract the mild cognitive impairment and synaptic loss observed in the early stages of AD.

Taken together, increasing evidence suggests that molecules belonging to several CAM families are engaged in neurogenesis, synaptic, and neuronal plasticity, all of which are affected by AD. Therefore, specific CAMs may constitute novel targets in strategies aimed at restoring these processes in $\mathrm{AD}$, which may ultimately lead to preserved cognitive functions.

\section{Evidence linking CAMs to $A \beta$ metabolism}

The significant association between $\mathrm{A} \beta$ - and AD-related synaptic alterations highlights the importance of elucidating the potential links between CAMs and the production, degradation, and biological functions of $A \beta$.

Immunohistological studies of brain tissue suggest that integrins may play a specific role in $A \beta$ pathology. Expression of the $\alpha 4$ integrin unit in hippocampal pyramidal neurons and some neocortical neurons is increased in aged individuals. ${ }^{62}$ Furthermore, increased expression of $\alpha 4$ and $\beta 3$, their ligands fibronectin, and vintronectin, as well as the CSK proteins, paxillin and hydrogen peroxide-inducible clone 5 (Hic-5), were found in plaques and/or tangles in $\mathrm{AD}$ brain tissue. ${ }^{62-64}$ Moreover, integrins may also mediate $A \beta$ neurotoxicity. For instance, when bound to integrins, $A \beta$ induced rapid phosphorylation of the NRTK focal adhesion kinase (FAK) and paxillin, which in turn activated an incomplete antiapoptotic signaling pathway and tau phosphorylation. ${ }^{65}$ It is worth noting that neuronal cells can be rescued from $A \beta$-induced downregulation of $\alpha 1 \beta 1$ and cell cycle arrest in the presence of $17 \beta$-estradiol, which suggesed an interesting mechanism underlying the previously demonstrated increase of AD in menopausal women. ${ }^{66}$ Interestingly, an in vitro study on human neuroblastoma cells suggested that the integrin receptor, $\alpha 5 \beta 1$ (cluster of differentiation [CD] $49 \mathrm{e})$, may play a role in the internalization and degradation of exogenous $A \beta .{ }^{67}$ Furthermore, the $\beta 1$ integrin could mediate the microglial internalization of fibrillar, ${ }^{68}$ but not soluble $A \beta,{ }^{69}$ suggesting that this integrin may be important 
at different stages of $\mathrm{AD}$, where for instance, $\mathrm{A} \beta$ becomes more fibrillar at more advanced disease stages.

Additional evidence supporting links between CAMs and $\mathrm{AD}$ pathology shows that adhesion based on $\mathrm{N}$-cadherin increased APP dimerization and $A \beta$ release, whereas the ratio of $A \beta 42 / 40$ was decreased. ${ }^{70,71}$ Another classical cadherin, epithelial cadherin (E-cadherin), also affected $A \beta$ levels. This cadherin subtype is primarily expressed on epithelial cells, ${ }^{72}$ but is also found on hippocampal synapses. ${ }^{73,74}$ E-cadherincatenin complexes recruit and can be cleaved by presenilin, similar to N-cadherin-catenin complexes. The cleavage product in this pathway, called carboxy-terminal fragment of E-cadherin (E-cad/CTF2), has been shown to promote the lysosomal degradation of APP derivates and to inhibit $\mathrm{A} \beta$ production. ${ }^{75}$

\section{CAMs in AD neuroinflammatory events}

Transendothelial migration of leukocytes to sites of inflammation is central to immunological processes that respond to tissue damage in the periphery. However, under certain conditions such as in multiple sclerosis (MS), ${ }^{76}$ brain malignancies, ${ }^{77,78}$ and brain infections, ${ }^{79-82}$ leukocytes can also infiltrate the central nervous system (CNS) by crossing the BBB. The migration of leukocytes depends on integrin expression on the surface of the leukocytes and Ig-CAMs, including the intercellular cell adhesion molecule 1 (ICAM-1), vascular cell adhesion molecule 1 (VCAM-1), and the platelet endothelial cell adhesion molecule (PECAM-1) present on endothelial cells. ${ }^{1}$ Expression of ICAM-1 can be upregulated in vitro on primary cultures of human brain microvessel endothelial cells by cytokines such as $\gamma$-interferon, interleukin (IL)-1, tumor necrosis factor- $\alpha$ (TNF- $\alpha$ ), and endotoxin. ${ }^{83}$ Experimental studies performed on human brain endothelial cells demonstrated an $\mathrm{A} \beta$-induced time-dependent increase in ICAM-1 and VCAM-1 expression. The same study showed the augmented adhesion and transendothelial migration of monocytic cells involving PECAM-1 upon A $\beta$ interaction. ${ }^{84}$ Interestingly, soluble ICAM-1 could block lymphocyte adhesion to cerebral endothelial cells, which stands in direct opposition to the role of cell-bound ICAM-1. ${ }^{15}$ Furthermore, it has been demonstrated that ICAM-1, VCAM-1, and PECAM-1 not only engage in transendothelial migration of leukocytes but also serve as signal transducers that initiate endothelial signaling and influence the progression of neuroinflammation. ${ }^{85}$ Increased levels of both ICAM-1 and PECAM-1 have also been proposed as indicators of inflammatory conditions in the $\mathrm{CNS}^{86,87}$ and could originate from activated glial cells. ${ }^{88}$ Similarly, Rentzos et al found increased ICAM-1 levels in AD in the absence of endothelial activation and, therefore, proposed a neural, rather than endothelial, origin of ICAM-1. ${ }^{89,90}$ The authors also displayed a positive correlation between increased levels of CSF ICAM-1 and disease severity, as assessed by mini-mental state examination (MMSE) scores.

The concentrations of the soluble forms of ICAM-1, VCAM-1, and PECAM-1 in patients with AD as well as other neurodegenerative diseases such as dementia with Lewy bodies (DLB) have been evaluated in several studies. ${ }^{89-92} \mathrm{In}$ patients with LOAD, Zuliani et al found increased levels of plasma VCAM- $1,{ }^{93}$ while this study found that AD and DLB patients exhibited higher plasma levels of soluble ICAM-1 and PECAM-1, but not VCAM-1 ${ }^{92}$ Discrepancies between the VCAM-1 plasma levels in these studies might be due to dementia severity $-\mathrm{AD}$ patients with moderate dementia may exhibit normal plasma VCAM-1 levels while patients with more severe dementia may exhibit different levels. ${ }^{92,93}$ Altered plasma levels of ICAM-1 were shown to be unrelated to the risk of dementia in non-demented individuals; therefore, increased levels might be secondary to the processes that lead to the onset of dementia. ${ }^{91}$ In direct opposition to the results on plasma, this review found that the CSF concentrations of VCAM-1 were significantly lower in patients with $\mathrm{AD}$ and DLB. In patients with AD, brain tissue ICAM-1 was repeatedly identified in plaques, ${ }^{94-96}$ however, this study only found increased CSF concentrations of soluble ICAM-1 in patients with DLB. ${ }^{92}$ Therefore, the soluble fraction of these CAMs may not necessarily reflect the amount of the cell-membranebound forms. In a recent study we also showed that CSF levels of ICAM-1 in female AD patients correlated with levels of hyaluronic acid, an adhesion molecule implicated in both inflammatory events and vascular changes. ${ }^{97}$ The main significance of the described altered levels of Ig-CAMs in $\mathrm{AD}$ requires further investigation as neuroinflammation in AD appears to take place without any apparent influx of leukocytes from the blood..$^{98}$ Thus, the altered levels of the soluble forms of Ig-CAMs may reflect inflammatory processes unrelated to cognitive performance (as assessed with MMSE). Alternatively, they may mediate functions that are currently unknown in relation to $\mathrm{AD}$ pathology.

In addition to Ig-CAMs, integrins can also be linked to $\mathrm{AD}$ neuroinflammation. The integrins on the surface of leukocytes are considered important for the presentation of antigen in the CNS. ${ }^{99}$ Similarly, microglia express several integrins that can be upregulated when the cells are activated in response to inflammation and injury. A recent 
study showed that microglia could interact with fibrillary $\mathrm{A} \beta$ through a complex including $\alpha 6 \beta 1$ and B-class scavenger receptor, CD36. This interaction induced proinflammatory activation of the microglia, which led to increased production of cytokines and chemokines. ${ }^{100}$ Moreover, results obtained from mixed neuron-glia cell cultures from cerebellum showed that neurons, when exposed to $A \beta$, signal a phagocytic request to microglia that is mediated through binding between phosphatidylserine (PS) on the neuron surface and the $\alpha v \beta 3 / 5$ integrin receptors on microglia. ${ }^{101}$ Other integrins such as $\alpha \mathrm{L} \beta 2$ (CD11a), $\alpha \mathrm{M} \beta 2$ (CD11b), and $\alpha \mathrm{X} \beta 2$ (CD11c) found in immunohistological studies on the temporal cortexes of $\mathrm{AD}$ patients, were found to be strongly upregulated on the surface of activated microglia in presence of $A \beta .{ }^{102}$ Antibodies blocking the microglial $\alpha \mathrm{M} \beta 2$ (CD11b) have also been shown to attenuate inflammatory reactions, vascular responses, and neurodegeneration induced by the injection of $A \beta$ into rat hippocampuses. ${ }^{103}$

The proinflammatory activation of microglia is also associated with changes in $\beta$-catenin, a protein that links cadherins to the intracellular actin. A study performed on brain tissue from AD patients and transgenic AD mice demonstrated the increased expression of $\beta$-catenin in activated morphologically transformed microglia. The authors of this study also used in vitro studies to show that Wnt signaling, a pathway controlling $\beta$-catenin metabolism, regulates the gene expression of microglial proinflammatory cytokines. ${ }^{104}$

Collectively, these data indicate that CAMs of the integrin and Ig-CAM families are involved in AD neuroinflammatory events, and some of these molecules may function as inflammation markers whereas others may play active roles in mediating inflammation.

\section{Role of CAMs in vascular changes linked to AD}

Several CAMs that are specifically involved in endothelial alterations, as imposed by vascular alterations and CAA in $\mathrm{AD}$, have been the focus of attention in studies aimed at characterizing the vascular component frequently found in AD. Based on the clinical and epidemiological evidence supporting the links between vascular risk factors and AD, Borroni et al investigated the peripheral blood concentrations of E-selectin in age-matched controls and AD patients with mild dementia. In line with the notion of endothelial dysfunction in $\mathrm{AD}$, the study demonstrated significantly increased E-selectin levels in the AD group, which indicates that endothelial dysfunction in AD could potentially be monitored in peripheral blood. ${ }^{105}$ However, two recent studies could not confirm altered E-selectin levels in AD patients. The authors of the latter studies investigated soluble CAMs in patients with various neurological disorders including AD patients without the vascular component. ${ }^{90,106}$ However, when the authors divided the subjects into groups with small or large vessel disease confirmed by computer tomography (CT) scans, the patients with vessel disease exhibited significantly increased E-selectin compared to the group with no vascular lesions. ${ }^{93}$ Therefore, altered E-selectin levels in AD appear to be related to cerebrovascular lesions.

In the periphery, platelets contain and metabolize the A $\beta$ precursor protein APP, and altered APP processing in platelets of AD patients has been suggested to reflect chronic platelet activation in these patients. ${ }^{107}$ Furthermore, treatment with acetylcholinesterase inhibitors (AChEI) influences APP metabolism in platelets, which may be modulated by the APOE genotype. ${ }^{108}$ Interestingly, platelet activation was recently reinvestigated and suggested as a prognostic biomarker for cognitive decline in AD patients. Patients with faster cognitive decline demonstrated significantly higher baseline expression of platelet activation markers including P-selectin. ${ }^{109}$ The authors of the study proposed several mechanisms for how platelet activity could contribute to dementia progression including triggering perivascular inflammation, induction of vasoconstriction, and consecutive brain hypoperfusion in addition to contributing to the peripheral $A \beta$ pool. In a recent study of platelet activation in sporadic AD patients, Järemo and colleagues found that circulating a lower density platelet population exhibits a reduced activation state, as assessed by the amount of platelet surface bound fibrinogen. ${ }^{110}$ Therefore, the activation of different platelet populations appears to be related to $\mathrm{AD}$. The role of $\mathrm{P}$-selectins in these processes is yet to be determined, but P-selectin antagonists, as modulators of inflammation, have been proposed in vascular pathologies such as atherosclerosis. ${ }^{11}$

Next to CAMs of the selectin family, integrins are also related to vascular processes. For instance, the increased expression of $\beta 3$ integrin on endothelial cells is a welldescribed marker for ongoing angiogenesis. ${ }^{12}$ Studies on brain tissue demonstrated upregulated $\alpha v \beta 3$ (CD51) expression in $\mathrm{AD}$ patients, ${ }^{113} \mathrm{a}$ finding that supports previous results proposing increased angiogenesis in AD patients. ${ }^{114}$ The upregulation of this integrin was also shown to correlate with $\mathrm{A} \beta$ load in the hippocampus and neurofibrillary tangles in the midfrontal cortex. ${ }^{113}$ Further investigation is required to determine whether there is a direct or an indirect link between $\alpha v \beta 3, A D$ pathology, and cognitive deterioration. In sum, the increasing evidence regarding the potential causal role 
of vascular factors in $\mathrm{AD}$ pathogenesis warrants the further investigation of CAMs.

\section{Currently available AD treatment options}

To date, there is no approved pharmaceutical drug for the prevention or cure of AD. Instead, the available therapy consists of symptomatic treatment based on glutamatergic and cholinergic alterations, which at certain stages of AD can slow the disease's progression by boosting neuronal activity. Acetylcholinesterase inhibitors were the first AD pharmaceuticals to be approved, and today, the second generation of AChEIs (donezepil, rivastigmine, and galantamine) is the first line of pharmacotherapy for mild to moderate AD. By blocking the enzyme, acetylcholinesterase, AChEIs prevent the breakdown of acetylcholine in the synaptic cleft and partly replace the cholinergic transmission that is lost in AD patients. ${ }^{115}$ AChEIs have also shown favorable effects on the documented impaired vasodilation ${ }^{116}$ and neurovascular coupling (regulation of blood flow demand in brain areas $)^{117,118}$ found in AD patients. Moreover, a number of studies have presented evidence of the antiinflammatory and antiamyloidogenic properties associated with AChEI. ${ }^{119,120}$ These findings can be related to the previously mentioned effects of AChEI on platelet APP metabolism. ${ }^{108}$

Memantine, a noncompetitive antagonist of the glutamate NMDA receptor, is the second type of medication approved for $\mathrm{AD}$ treatment and has documented effects alone or in combination with AChEI on moderate to severe AD. Its primary effect is the inhibition of pathological activation of NMDARs, which prevent excessive glutamatergicallyinduced $\mathrm{Ca}^{2+}$ influx and cell death. ${ }^{121}$ In addition, results from preclinical studies suggest that memantine and NMDA antagonists could reduce the secretion of proinflammatory cytokines by blocking glutamate receptors on glial cells and thereby slowing neuroinflammation, ${ }^{122}$ protecting against $\mathrm{BBB}$ breakdown, ${ }^{123}$ reducing $\mathrm{A} \beta$ production, ${ }^{124,125}$ and $\mathrm{A} \beta$ neurotoxicity. ${ }^{126}$ However, $\mathrm{AD}$ is without a remedy despite the various beneficial effects of AChEIs and memantine and the laborious efforts of trying to find a cure. Therefore, the importance of research aimed at identifying the underlying AD mechanisms, which could yield new pharmaceutical targets, cannot be exaggerated.

\section{Significance of CAMs in potential treatment strategies}

In light of the reported involvement of CAMs in the various aspects of $\mathrm{AD}$, these molecules may offer new unexplored treatment opportunities and when used as biomarkers that can provide potential tools to enable the clinical monitoring of AD related inflammation and cerebrovascular complications, disease progression, and treatment response. Depending on the overall treatment goal - prevention, disease-modification, or cure - different aspects of AD may need to be targeted.

\section{Strategies to counteract neuroinflammation}

In investigations of long-term use of anti-inflammatory agents, nonsteroidal anti-inflammatory drugs (NSAIDs) have shown beneficial effects in terms of reducing the risk of developing AD. ${ }^{127}$ Moreover, long-term treatment responses to cholinesterase inhibitors were better in individuals treated with NSAIDs. ${ }^{128}$ However, recently published extended results of the AD anti-inflammatory prevention trial (ADAPT) demonstrated that treatment with NSAIDs might have an adverse effect in the later stages of $\mathrm{AD},{ }^{129}$ which indicates that inflammatory processes might shift from acute to chronic, meaning different pathways may be engaged. Anti-selectin substances have been suggested as another potential treatment to control inflammatory disease. However, similar to NSAID treatment, the timing of treatment may be of crucial importance. ${ }^{130}$ Finally, due to the significant association between inflammatory events, AD pathology, ${ }^{131,132}$ and increased levels of ICAM-1, it is necessary to emphasize the importance of evaluating the various roles of the soluble and membrane-bound forms of ICAM-1. Targeting ICAM-1 in animal models of reperfusion injuries demonstrated a neuroprotective effect of anti-ICAM administration. ${ }^{133,134}$ In addition, ICAM-1 levels in cognitively conserved elderly patients have been linked to decreased parietal blood flow. ${ }^{135}$ Therefore, the elucidation of altered ICAM-1 expression as a consequence or disease modifying component may identify this molecule as a potential target for future anti-inflammatory AD treatment options.

\section{Strategies aimed at altering A $\beta$ metabolism}

One of the reported effects of the AChEI rivastigmine is the modulation of secretase activity, which results in decreased A $\beta$ secretion. ${ }^{136}$ Therefore, interference with the proteolytic generation of the $A \beta$ peptide by inhibition of $\beta$-secretase and $\gamma$-secretase activity could prove beneficial. However, $\beta$ and $\gamma$-secretase inhibitors, as well as $\gamma$-secretase modulators, are yet to prove successful in clinical trials. ${ }^{137}$ An alternative approach could be to target competition for secretase 
activity by taking advantage of certain mechanisms such as the recruitment of presenilin to the cadherin-catenin complex at the expense of presenilin $/ \gamma$-secretase cleavage of APP. ${ }^{59}$

Elimination of already deposited $A \beta$ is another strategy for eradicating $A \beta$ toxicity. For this purpose, both active and passive immunization against $A \beta$ have been evaluated. The administration of pre-aggregated or soluble $A \beta$ generated an antibody response and $\mathrm{A} \beta$ plaque reduction in aged animals. However, due to serious adverse effects with aseptic meningoencephalitis caused by T-cell activation in a subset of patients, ${ }^{138}$ the initial clinical trial was interrupted. A new generation of active $A \beta$ immunization using $A \beta$ fragments, without the ability to activate T-cells, has currently entered Phase I trials. ${ }^{137}$ An anti-CAM treatment could be useful to circumvent adverse immunization effects such as the influx of leukocytes into the CNS. Lessons learned from the field of MS research, including its animal model experimental autoimmune encephalomyelitis (EAE), suggest anti-integrin $(\alpha 4)$ treatment as a measure of preventing leukocyte influx. ${ }^{139}$ Passive immunization strategies using humanized monoclonal antibodies directed against different sites of $A \beta$ have shown improved cognitive functions in APOE carriers as well as reduced brain atrophy in APOE non-carrier in Phase II trials. Moreover, intravenously delivered immunoglobulins isolated from pooled human blood (IVIgs) were found to significantly reduce both $\mathrm{A} \beta$ plaques and inflammatory events in $\mathrm{AD}$ patients. ${ }^{137}$

Enhanced $A \beta$ clearance can also be achieved via targeted gene delivery by use of CAM-dependent transendothelial migration. For instance, a recent study convincingly showed that endogenous $\mathrm{CD} 11 \mathrm{~b}+$ bone marrow cells home to $\mathrm{A} \beta$ plaques in the brain of $\mathrm{AD}$ transgenic mice. The study further demonstrated that subcutaneous infusion of $\mathrm{CD} 11 \mathrm{~b}+$ bone marrow cells transfected with the gene coding for neprilysin, an $A \beta$-degrading enzyme, and completely arrested $A \beta$ deposition. ${ }^{140}$ Therefore, using CAM-dependent mechanisms to introduce cells harboring the appropriate genes into the CNS has large-scale potential.

\section{Strategies targeting vascular alterations}

Given the reported association between vascular risk factors and $\mathrm{AD},{ }^{29}$ it is worth noting that activation of different platelet populations, which is also linked to vascular alterations and stroke, ${ }^{141}$ appears also related to $\mathrm{AD}^{110}$ and altered APP metabolism. ${ }^{107}$ Since the activation of platelets involves alterations in P-selectin expression ${ }^{142}$ as well as integrin $\alpha \mathrm{IIb} \beta$ complex activation, ${ }^{142}$ and since these molecules possibly regulate inflammatory processes, ${ }^{112}$ which are known to affect the vasculature, it is necessary to perform intensified studies that elucidate the potential of targeting platelet adhesion molecules in AD.

\section{Conclusion}

This review summarized current knowledge of CAMs associated with $\mathrm{AD}$, as well as the potential clinical utility of CAMs as disease biomarkers or pharmaceutical targets in novel AD treatment strategies. It has also identified a major need for both experimental and clinical studies to characterize the specific mechanisms by which CAMs relate to AD. Numerous observational studies have reported altered levels of CAMs in $\mathrm{AD}$, but the specific roles of CAMs as markers or mediators of biological events leading to cognitive deterioration and dementia remain undetermined.

\section{Acknowledgments}

The authors wish to acknowledge the Swedish Brain Power initiative and ALF (the regional agreement on medical training and clinical research between the Skåne County Council and Lund University) for financial support.

\section{Disclosure}

The authors report no conflicts of interest in this work.

\section{References}

1. Ley K, Laudanna C, Cybulsky MI, Nourshargh S. Getting to the site of inflammation: the leukocyte adhesion cascade updated. Nat Rev Immunol. 2007;7(9):678-689.

2. Bevilacqua MP, Nelson RM. Selectins. J Clin Invest. 1993;91(2): 379-387.

3. Buhrer C, Herold R, Stibenz D, Henze G, Obladen M. Cerebrospinal fluid soluble L-selectin (sCD62L) in meningoencephalitis. Arch Dis Child. 1996;74(4):288-292.

4. Dore-Duffy P, Newman W, Balabanov R, et al. Circulating, soluble adhesion proteins in cerebrospinal fluid and serum of patients with multiple sclerosis: correlation with clinical activity. Ann Neurol. 1995; 37(1):55-62

5. Whalen MJ, Carlos TM, Kochanek PM, et al. Soluble adhesion molecules in CSF are increased in children with severe head injury. J Neurotrauma. 1998;15(10):777-787.

6. Gearing AJ, Newman W. Circulating adhesion molecules in disease. Immunol Today. 1993;14(10):506-512.

7. Hynes RO. Integrins: bidirectional, allosteric signaling machines. Cell. September 20, 2002;110(6):673-687.

8. Reichardt LF, Prokop A. Introduction: The role of extracellular matrix in nervous system development and maintenance. Developmental neurobiology. Nov 2011;71(11):883-888.

9. Wu X, Reddy DS. Integrins as receptor targets for neurological disorders. J Pharmacol Pharmacother. 2012;134(1):68-81.

10. Evans BJ, McDowall A, Taylor PC, Hogg N, Haskard DO, Landis RC Shedding of lymphocyte function-associated antigen-1 (LFA-1) in a human inflammatory response. Blood. May 1, 2006;107(9): 3593-3599.

11. Marchetti PJ, O’Connor P. Cellular adhesion molecules in neurology. Can J Neurol Sci. 1997;24(3):200-209. 
12. Williams AF, Barclay AN. The immunoglobulin superfamily - domains for cell surface recognition. Annu Rev Immunol. 1988;6:381-405.

13. Lai C, Watson JB, Bloom FE, Sutcliffe JG, Milner RJ. Neural protein 1B236/myelin-associated glycoprotein (MAG) defines a subgroup of the immunoglobulin superfamily. Immunol Rev. 1987;100: 129-151.

14. Golias C, Tsoutsi E, Matziridis A, Makridis P, Batistatou A, Charalabopoulos K. Review. Leukocyte and endothelial cell adhesion molecules in inflammation focusing on inflammatory heart disease. In Vivo. 2007;21(5):757-769.

15. Rieckmann P, Michel U, Albrecht M, Bruck W, Wockel L, Felgenhauer K. Soluble forms of intercellular adhesion molecule-1 (ICAM-1) block lymphocyte attachment to cerebral endothelial cells. J Neuroimmunol. 1995;60(1-2):9-15.

16. Frank M, Kemler R. Protocadherins. Curr Opin Cell Biol. 2002; 14(5):557-562.

17. Arikkath J, Reichardt LF. Cadherins and catenins at synapses: roles in synaptogenesis and synaptic plasticity. Trends Neurosci. 2008;31(9):487-494.

18. Kopan R, Ilagan MX. $\gamma$-Secretase: proteasome of the membrane? Nat Rev Mol Cell Biol. 2004;5(6):499-504.

19. Hyman BT, Trojanowski JQ. Consensus recommendations for the postmortem diagnosis of Alzheimer disease from the National Institute on Aging and the Reagan Institute Working Group on diagnostic criteria for the neuropathological assessment of Alzheimer disease. J Neuropathol Exp Neurol. 1997;56(10):1095-1097.

20. Hardy JA, Higgins GA. Alzheimer's disease: the amyloid cascade hypothesis. Science. 1992;256(5054):184-185.

21. Citron M. Alzheimer's disease: strategies for disease modification. Nat Rev Drug Discov. 2010;9(5):387-398.

22. Bertram L, Lill CM, Tanzi RE. The genetics of Alzheimer disease: back to the future. Neuron. 2010;68(2):270-281.

23. Corder EH, Saunders AM, Strittmatter WJ, et al. Gene dose of apolipoprotein E type 4 allele and the risk of Alzheimer's disease in late onset families. Science. 1993;261(5123):921-923.

24. Holtzman DM, Bales KR, Tenkova T, et al. Apolipoprotein E isoform-dependent amyloid deposition and neuritic degeneration in a mouse model of Alzheimer's disease. Proc Natl Acad Sci U S A. 2000;97(6):2892-2897.

25. Lee YJ, Han SB, Nam SY, Oh KW, Hong JT. Inflammation and Alzheimer's disease. Arch Pharm Res. 2010;33(10):1539-1556.

26. Eikelenboom P, van Exel E, Hoozemans JJ, Veerhuis R, Rozemuller AJ, van Gool WA. Neuroinflammation - an early event in both the history and pathogenesis of Alzheimer's disease. Neurodegener Dis. 2010;7(1-3):38-41.

27. Rojo LE, Fernandez JA, Maccioni AA, Jimenez JM, Maccioni RB. Neuroinflammation: implications for the pathogenesis and molecular diagnosis of Alzheimer's disease. Arch Med Res. 2008;39(1):1-16.

28. de la Torre JC. Vascular basis of Alzheimer's pathogenesis. Ann N Y Acad Sci. 2002;977:196-215.

29. Breteler MM. Vascular risk factors for Alzheimer's disease: an epidemiologic perspective. Neurobiol Aging. 2000;21(2):153-160.

30. Love S, Miners S, Palmer J, Chalmers K, Kehoe P. Insights into the pathogenesis and pathogenicity of cerebral amyloid angiopathy. Front Biosci. 2009;14:4778-4792.

31. Ondrejcak T, Klyubin I, Hu NW, Barry AE, Cullen WK, Rowan MJ. Alzheimer's disease amyloid beta-protein and synaptic function. Neuromolecular Med. 2010;12(1):13-26.

32. Rupsingh R, Borrie M, Smith M, Wells JL, Bartha R. Reduced hippocampal glutamate in Alzheimer disease. Neurobiol Aging. 2011;32(5):802-810.

33. Sims NR, Bowen DM, Allen SJ, et al. Presynaptic cholinergic dysfunction in patients with dementia. J Neurochem. 1983;40(2):503-509.

34. Bennett DA, Schneider JA, Wilson RS, Bienias JL, Arnold SE. Neurofibrillary tangles mediate the association of amyloid load with clinical Alzheimer disease and level of cognitive function. Arch Neurol. 2004;61(3):378-384.
35. McKhann GM, Knopman DS, Chertkow H, et al. The diagnosis of dementia due to Alzheimer's disease: recommendations from the National Institute on Aging-Alzheimer's Association workgroups on diagnostic guidelines for Alzheimer's disease. Alzheimers Dement. 2011;7(3):263-269.

36. DeKosky ST, Scheff SW. Synapse loss in frontal cortex biopsies in Alzheimer's disease: correlation with cognitive severity. Ann Neurol. 1990;27(5):457-464.

37. Terry RD, Masliah E, Salmon DP, et al. Physical basis of cognitive alterations in Alzheimer's disease: synapse loss is the major correlate of cognitive impairment. Ann Neurol. 1991;30(4):572-580.

38. Masliah E, Mallory M, Alford M, et al. Altered expression of synaptic proteins occurs early during progression of Alzheimer's disease. Neurology. 2001;56(1):127-129.

39. Scheff SW, Price DA, Schmitt FA, DeKosky ST, Mufson EJ. Synaptic alterations in CA1 in mild Alzheimer disease and mild cognitive impairment. Neurology. 2007;68(18):1501-1508.

40. Rodriguez JJ, Verkhratsky A. Neurogenesis in Alzheimer's disease. J Anat. 2011;219(1):78-89.

41. Eriksson PS, Perfilieva E, Bjork-Eriksson T, et al. Neurogenesis in the adult human hippocampus. Nat Med. 1998;4(11):1313-1317.

42. Alvarez-Buylla A, Garcia-Verdugo JM. Neurogenesis in adult subventricular zone. J Neurosci. 2002;22(3):629-634.

43. Mikkonen M, Soininen H, Tapiola T, Alafuzoff I, Miettinen R. Hippocampal plasticity in Alzheimer's disease: changes in highly polysialylated NCAM immunoreactivity in the hippocampal formation. Eur J Neurosci. 1999;11(5):1754-1764.

44. Jin K, Peel AL, Mao XO, et al. Increased hippocampal neurogenesis in Alzheimer's disease. Proc Natl Acad Sci U S A. 6, 2004;101(1): 343-347.

45. Aisa B, Gil-Bea FJ, Solas M, et al. Altered NCAM expression associated with the cholinergic system in Alzheimer's disease. J Alzheimers Dis. 2010;20(2):659-668.

46. Yew DT, Li WP, Webb SE, Lai HW, Zhang L. Neurotransmitters, peptides, and neural cell adhesion molecules in the cortices of normal elderly humans and Alzheimer patients: a comparison. Exp Gerontol. 1999;34(1):117-133.

47. Fazeli MS, Breen K, Errington ML, Bliss TV. Increase in extracellular NCAM and amyloid precursor protein following induction of long-term potentiation in the dentate gyrus of anaesthetized rats. Neurosci Lett. 1994;169(1-2):77-80.

48. Yin GN, Lee HW, Cho JY, Suk K. Neuronal pentraxin receptor in cerebrospinal fluid as a potential biomarker for neurodegenerative diseases. Brain Res. 2009;1265:158-170.

49. Strekalova H, Buhmann C, Kleene R, et al. Elevated levels of neural recognition molecule L1 in the cerebrospinal fluid of patients with Alzheimer disease and other dementia syndromes. Neurobiol Aging. 2006;27(1):1-9.

50. Miura M, Asou H, Kobayashi M, Uyemura K. Functional expression of a full-length cDNA coding for rat neural cell adhesion molecule L1 mediates homophilic intercellular adhesion and migration of cerebellar neurons. J Biol Chem. 1992;267(15):10752-10758.

51. Giagtzoglou N, Ly CV, Bellen HJ. Cell adhesion, the backbone of the synapse: "vertebrate" and "invertebrate" perspectives. Cold Spring Harb Perspect Biol. 2009;1(4):a003079.

52. Uemura K, Kuzuya A, Aoyagi N, et al. Amyloid beta inhibits ectodomain shedding of $\mathrm{N}$-cadherin via down-regulation of cell-surface NMDA receptor. Neuroscience. 2007;145(1):5-10.

53. Kong LN, Zuo PP, Mu L, Liu YY, Yang N. Gene expression profile of amyloid beta protein-injected mouse model for Alzheimer disease. Acta Pharmacol Sin. 2005;26(6):666-672.

54. Ando K, Uemura K, Kuzuya A, et al. N-cadherin regulates p38 MAPK signaling via association with JNK-associated leucine zipper protein: implications for neurodegeneration in Alzheimer disease. J Biol Chem. 2011;286(9):7619-7628.

55. Herlaar E, Brown Z. p38 MAPK signalling cascades in inflammatory disease. Mol Med Today. 1999;5(10):439-447. 
56. Heilig EA, Xia W, Shen J, Kelleher RJ 3rd. A presenilin-1 mutation identified in familial Alzheimer disease with cotton wool plaques causes a nearly complete loss of gamma-secretase activity. J Biol Chem. 2010;285(29):22350-22359.

57. Marambaud $\mathrm{P}$, Wen $\mathrm{PH}$, Dutt A, et al. A CBP binding transcriptional repressor produced by the PS1/epsilon-cleavage of $\mathrm{N}$-cadherin is inhibited by PS1 FAD mutations. Cell. 2003;114(5):635-645.

58. Saura CA, Valero J. The role of CREB signaling in Alzheimer's disease and other cognitive disorders. Rev Neurosci. 2011;22(2):153-169.

59. Kouchi Z, Barthet G, Serban G, Georgakopoulos A, Shioi J, Robakis NK. p120 catenin recruits cadherins to gamma-secretase and inhibits production of Abeta peptide. J Biol Chem. 2009;284(4):1954-1961.

60. Uemura K, Kuzuya A, Shimohama S. Protein trafficking and Alzheimer's disease. Curr Alzheimer Res. 2004;1(1):1-10.

61. Rowan MJ, Klyubin I, Wang Q, Hu NW, Anwyl R. Synaptic memory mechanisms: Alzheimer's disease amyloid beta-peptide-induced dysfunction. Biochem Soc Trans. 2007;35(Pt 5):1219-1223.

62. Van Gool D, Carmeliet G, Triau E, Cassiman JJ, Dom R. Appearance of localized immunoreactivity for the alpha 4 integrin subunit and for fibronectin in brains from Alzheimer's, Lewy body dementia patients and aged controls. Neurosci Lett. 1994;170(1):71-73.

63. Akiyama H, Kawamata T, Dedhar S, McGeer PL. Immunohistochemical localization of vitronectin, its receptor and beta-3 integrin in Alzheimer brain tissue. J Neuroimmunol. 1991;32(1):19-28.

64. Caltagarone J, Hamilton RL, Murdoch G, Jing Z, DeFranco DB, Bowser R. Paxillin and hydrogen peroxide-inducible clone 5 expression and distribution in control and Alzheimer disease hippocampi. J Neuropathol Exp Neurol. 2010;69(4):356-371.

65. Caltagarone J, Jing Z, Bowser R. Focal adhesions regulate Abeta signaling and cell death in Alzheimer's disease. Biochim Biophys Acta. 2007;1772(4):438-445.

66. Bozzo C, Graziola F, Chiocchetti A, Canonico PL. Estrogen and beta-amyloid toxicity: role of integrin and PI3-K. Mol Cell Neurosci. 2010;45(2):85-91.

67. Matter ML, Zhang Z, Nordstedt C, Ruoslahti E. The alpha5beta1 integrin mediates elimination of amyloid-beta peptide and protects against apoptosis. J Cell Biol. 1998;141(4):1019-1030.

68. Koenigsknecht J, Landreth G. Microglial phagocytosis of fibrillar betaamyloid through a beta1 integrin-dependent mechanism. J Neurosci. 2004;24(44):9838-9846.

69. Mandrekar S, Jiang Q, Lee CY, Koenigsknecht-Talboo J, Holtzman DM, Landreth GE. Microglia mediate the clearance of soluble Abeta through fluid phase macropinocytosis. J Neurosci. 2009;29(13) 4252-4262.

70. Asada-Utsugi M, Uemura K, Noda Y, et al. N-cadherin enhances APP dimerization at the extracellular domain and modulates $\mathrm{A} \beta$ production. J Neurochem. 2011;119(2):354-363.

71. Uemura K, Lill CM, Banks M, et al. N-cadherin-based adhesion enhances Abeta release and decreases Abeta42/40 ratio. J Neurochem. 2009;108(2):350-360.

72. Shapiro L, Love J, Colman DR. Adhesion molecules in the nervous system: structural insights into function and diversity. Annu Rev Neurosci. 2007;30:451-474.

73. Fiederling A, Ewert R, Andreyeva A, Jungling K, Gottmann K. E-cadherin is required at GABAergic synapses in cultured cortical neurons. Neurosci Lett. 2011;501(3):167-172.

74. Tang L, Hung CP, Schuman EM. A role for the cadherin family of cell adhesion molecules in hippocampal long-term potentiation. Neuron. 1998;20(6):1165-1175.

75. Agiostratidou G, Muros RM, Shioi J, Marambaud P, Robakis NK. The cytoplasmic sequence of E-cadherin promotes non-amyloidogenic degradation of A beta precursors. J Neurochem. 2006;96(4):1182-1188.

76. Engelhardt B. Immune cell entry into the central nervous system: involvement of adhesion molecules and chemokines. J Neurol Sci. 15, 2008;274(1-2):23-26.

77. D'Abaco GM, Kaye AH. Integrins: molecular determinants of glioma invasion. J Clin Neurosci. 2007;14(11):1041-1048.
78. Barami K, Lewis-Tuffin L, Anastasiadis PZ. The role of cadherins and catenins in gliomagenesis. Neurosurg Focus. 2006;21(4):E13.

79. Brankin B, Hart MN, Cosby SL, Fabry Z, Allen IV. Adhesion molecule expression and lymphocyte adhesion to cerebral endothelium effects of measles virus and herpes simplex 1 virus. J Neuroimmunol. 1995;56(1):1-8.

80. Ou R, Zhang M, Huang L, Flavell RA, Koni PA, Moskophidis D. Regulation of immune response and inflammatory reactions against viral infection by VCAM-1. J Virol. 2008;82(6):2952-2965.

81. Sasseville VG, Lane JH, Walsh D, Ringler DJ, Lackner AA. VCAM-1 expression and leukocyte trafficking to the CNS occur early in infection with pathogenic isolates of SIV. J Med Primatol. 1995;24(3):123-131.

82. Sasseville VG, Newman W, Brodie SJ, Hesterberg P, Pauley D, Ringler DJ. Monocyte adhesion to endothelium in simian immunodeficiency virus-induced AIDS encephalitis is mediated by vascular cell adhesion molecule-1/alpha 4 beta 1 integrin interactions. Am J Pathol. 1994;144(1):27-40.

83. Wong D, Dorovini-Zis K. Upregulation of intercellular adhesion molecule-1 (ICAM-1) expression in primary cultures of human brain microvessel endothelial cells by cytokines and lipopolysaccharide. J Neuroimmunol. 1992;39(1-2):11-21.

84. Giri R, Shen Y, Stins M, et al. beta-amyloid-induced migration of monocytes across human brain endothelial cells involves RAGE and PECAM-1. Am J Physiol Cell Physiol. 2000;279(6) C1772-C1781.

85. Greenwood J, Etienne-Manneville S, Adamson P, Couraud PO. Lymphocyte migration into the central nervous system: implication of ICAM-1 signalling at the blood-brain barrier. Vascul Pharmacol. 2002;38(6):315-322.

86. Kalinowska A, Losy J. PECAM-1, a key player in neuroinflammation. Eur J Neurol. 2006;13(12):1284-1290.

87. Rieckmann P, Nunke K, Burchhardt M, et al. Soluble intercellular adhesion molecule-1 in cerebrospinal fluid: an indicator for the inflammatory impairment of the blood-cerebrospinal fluid barrier. J Neuroimmunol. 1993;47(2):133-140.

88. Lee SJ, Benveniste EN. Adhesion molecule expression and regulation on cells of the central nervous system. J Neuroimmunol. 3, 1999;98(2):77-88

89. Rentzos M, Michalopoulou M, Nikolaou C, et al. Serum levels of soluble intercellular adhesion molecule-1 and soluble endothelial leukocyte adhesion molecule-1 in Alzheimer's disease. J Geriatr Psychiatry Neurol. 2004;17(4):225-231.

90. Rentzos M, Michalopoulou M, Nikolaou C, et al. The role of soluble intercellular adhesion molecules in neurodegenerative disorders. J Neurol Sci. 15, 2005;228(2):129-135.

91. Engelhart MJ, Geerlings MI, Meijer J, et al. Inflammatory proteins in plasma and the risk of dementia: the Rotterdam study. Arch Neurol. 2004;61(5):668-672.

92. Nielsen HM, Londos E, Minthon L, Janciauskiene SM. Soluble adhesion molecules and angiotensin-converting enzyme in dementia. Neurobiol Dis. 2007;26(1):27-35.

93. Zuliani G, Cavalieri M, Galvani M, et al. Markers of endothelial dysfunction in older subjects with late onset Alzheimer's disease or vascular dementia. J Neurol Sci. 2008;272(1-2):164-170.

94. Eikelenboom P, Zhan SS, Kamphorst W, van der Valk P, Rozemuller JM. Cellular and substrate adhesion molecules (integrins) and their ligands in cerebral amyloid plaques in Alzheimer's disease. Virchows Arch. 1994;424(4):421-427.

95. Frohman EM, Frohman TC, Gupta S, de Fougerolles A, van den Noort S. Expression of intercellular adhesion molecule 1 (ICAM-1) in Alzheimer's disease. J Neurol Sci. 1991;106(1):105-111.

96. Rozemuller JM, Eikelenboom P, Pals ST, Stam FC. Microglial cells around amyloid plaques in Alzheimer's disease express leucocyte adhesion molecules of the LFA-1 family. Neurosci Lett. 1989;101(3):288-292. 
97. Nielsen HM, Palmqvist S, Minthon L, Londos E, Wennstrom M. Gender-dependent levels of hyaluronic acid in cerebrospinal fluid of patients with neurodegenerative dementia. Curr Alzheimer Res. 2012;9(3):257-266.

98. Eikelenboom P, Rozemuller AJ, Hoozemans JJ, Veerhuis R, van Gool WA. Neuroinflammation and Alzheimer disease: clinical and therapeutic implications. Alzheimer Dis Assoc Disord. 2000; 14 Suppl 1:S54-S61.

99. Hogg N, Patzak I, Willenbrock F. The insider's guide to leukocyte integrin signalling and function. Nat Rev Immunol. 2011;11(6): 416-426.

100. Bamberger ME, Harris ME, McDonald DR, Husemann J, Landreth GE. A cell surface receptor complex for fibrillar betaamyloid mediates microglial activation. J Neurosci. 2003;23(7): 2665-2674.

101. Neniskyte U, Neher JJ, Brown GC. Neuronal death induced by nanomolar amyloid beta is mediated by primary phagocytosis of neurons by microglia. J Biol Chem. 2011;286(46):39904-39913.

102. Akiyama H, McGeer PL. Brain microglia constitutively express beta-2 integrins. J Neuroimmunol. 1990;30(1):81-93.

103. Ryu JK, McLarnon JG. A leaky blood-brain barrier, fibrinogen infiltration and microglial reactivity in inflamed Alzheimer's disease brain. J Cell Mol Med. 2009;13(9A):2911-2925.

104. Halleskog C, Mulder J, Dahlstrom J, et al. WNT signaling in activated microglia is proinflammatory. Glia. 2011;59(1):119-131.

105. Borroni B, Volpi R, Martini G, et al. Peripheral blood abnormalities in Alzheimer disease: evidence for early endothelial dysfunction. Alzheimer Dis Assoc Disord. 2002;16(3):150-155.

106. Rentzos M, Michalopoulou M, Nikolaou C, et al. Serum levels of soluble intercellular adhesion molecule-1 and soluble endothelial leukocyte adhesion molecule-1 in Alzheimer's disease. J Geriatr Psychiatry Neurol. 2004;17(4):225-231.

107. Rosenberg RN, Baskin F, Fosmire JA, et al. Altered amyloid protein processing in platelets of patients with Alzheimer disease. Arch Neurol. 1997;54(2):139-144.

108. Borroni B, Colciaghi F, Pastorino L, et al. ApoE genotype influences the biological effect of donepezil on APP metabolism in Alzheimer disease: evidence from a peripheral model. Eur Neuropsychopharmacol. 2002;12(3):195-200.

109. Stellos K, Panagiota V, Kogel A, Leyhe T, Gawaz M, Laske C. Predictive value of platelet activation for the rate of cognitive decline in Alzheimer's disease patients. J Cereb Blood Flow Metab. 2010;30(11):1817-1820.

110. Jaremo P, Milovanovic M, Buller C, Nilsson S, Winblad B. Low-density platelet populations demonstrate low in vivo activity in sporadic Alzheimer disease. Platelets. 2012;23(2):116-120.

111. Woollard KJ, Chin-Dusting J. P-selectin antagonism in inflammatory disease. Curr Pharm Des. 2010;16(37):4113-4118.

112. Beer AJ, Schwaiger M. Imaging of integrin alphavbeta3 expression. Cancer Metastasis Rev. 2008;27(4):631-644.

113. Desai BS, Schneider JA, Li JL, Carvey PM, Hendey B. Evidence of angiogenic vessels in Alzheimer's disease. J Neural Transm. 2009; 116(5):587-597.

114. Grammas P, Sanchez A, Tripathy D, Luo E, Martinez J. Vascular signaling abnormalities in Alzheimer disease. Cleve Clin J Med. 2011; 78(Suppl 1):S50-S53.

115. Francis PT, Palmer AM, Snape M, Wilcock GK. The cholinergic hypothesis of Alzheimer's disease: a review of progress. J Neurol Neurosurg Psychiatry. 1999;66(2):137-147.

116. Bar KJ, Boettger MK, Seidler N, Mentzel HJ, Terborg C, Sauer H. Influence of galantamine on vasomotor reactivity in Alzheimer's disease and vascular dementia due to cerebral microangiopathy. Stroke. 2007;38(12):3186-3192.

117. Rosengarten B, Lutz H, Kaps M. The neurovascular coupling bears properties of a feedforward and feedback regulative mechanism. Ultrasound Med Biol. 2008;34(1):1-6.
118. Rosengarten B, Paulsen S, Molnar S, Kaschel R, Gallhofer B, Kaps M. Acetylcholine esterase inhibitor donepezil improves dynamic cerebrovascular regulation in Alzheimer patients. J Neurol. 2006;253(1):58-64.

119. Hwang J, Hwang H, Lee HW, Suk K. Microglia signaling as a target of donepezil. Neuropharmacology. 2010;58(7):1122-1129.

120. Yoshiyama Y, Kojima A, Ishikawa C, Arai K. Anti-inflammatory action of donepezil ameliorates tau pathology, synaptic loss, and neurodegeneration in a tauopathy mouse model. J Alzheimers Dis. 2010;22(1):295-306.

121. Osborn GG, Saunders AV. Current treatments for patients with Alzheimer disease. J Am Osteopath Assoc. 2010;110(9 Suppl 8): S16-S26.

122. Rosi S, Ramirez-Amaya V, Vazdarjanova A, et al. Accuracy of hippocampal network activity is disrupted by neuroinflammation: rescue by memantine. Brain. Sep 2009;132(Pt 9):2464-2477.

123. Paul C, Bolton C. Modulation of blood-brain barrier dysfunction and neurological deficits during acute experimental allergic encephalomyelitis by the N-methyl-D-aspartate receptor antagonist memantine. J Pharmacol Exp Ther. 2002;302(1):50-57.

124. Bordji K, Becerril-Ortega J, Buisson A. Synapses, NMDA receptor activity and neuronal Abeta production in Alzheimer's disease. Rev Neurosci. 2011;22(3):285-294.

125. Ray B, Banerjee PK, Greig NH, Lahiri DK. Memantine treatment decreases levels of secreted Alzheimer's amyloid precursor protein (APP) and amyloid beta (A beta) peptide in the human neuroblastoma cells. Neurosci Lett. 2010;470(1):1-5.

126. Harkany T, Hortobagyi T, Sasvari M, et al. Neuroprotective approaches in experimental models of beta-amyloid neurotoxicity: relevance to Alzheimer's disease. Prog Neuropsychopharmacol Biol Psychiatry. 1999;23(6):963-1008.

127. in't Veld BA, Ruitenberg A, Hofman A, et al. Nonsteroidal antiinflammatory drugs and the risk of Alzheimer's disease. $N$ Engl J Med. 2001;345(21):1515-1521.

128. Wattmo C, Wallin AK, Londos E, Minthon L. Predictors of longterm cognitive outcome in Alzheimer's disease. Alzheimers Res Ther. 2011;3(4):23.

129. Breitner JC, Baker LD, Montine TJ, et al. Extended results of the Alzheimer's disease anti-inflammatory prevention trial. Alzheimers Dement. 2011;7(4):402-411.

130. Rossi B, Constantin G. Anti-selectin therapy for the treatment of inflammatory diseases. Inflamm Allergy Drug Targets. 2008;7(2):85-93.

131. Verbeek MM, Otte-Holler I, Wesseling P, Ruiter DJ, de Waal RM. Differential expression of intercellular adhesion molecule-1 (ICAM-1) in the A beta-containing lesions in brains of patients with dementia of the Alzheimer type. Acta Neuropathol. 1996;91(6):608-615.

132. Verbeek MM, Otte-Holler I, Westphal JR, Wesseling P, Ruiter DJ, de Waal RM. Accumulation of intercellular adhesion molecule-1 in senile plaques in brain tissue of patients with Alzheimer's disease. Am J Pathol. 1994;144(1):104-116.

133. Cao J, Shi X, Li W, Liu J, Miao X, Xu J. Protective effect of anti-intercellular adhesion molecule-1 antibody on global cerebral ischemia/ reperfusion injury in the rat. Biosci Trends. 2009;3(2):48-52.

134. Kanemoto Y, Nakase H, Akita N, Sakaki T. Effects of anti-intercellular adhesion molecule-1 antibody on reperfusion injury induced by late reperfusion in the rat middle cerebral artery occlusion model. Neurosurgery. 2002;51(4):1034-1041, [discussion 1041-1042].

135. Janciauskiene SM, Erikson C, Warkentin S. A link between sICAM-1, ACE and parietal blood flow in the aging brain. Neurobiol Aging. 2009;30(9):1504-1511.

136. Bailey JA, Ray B, Greig NH, Lahiri DK. Rivastigmine lowers Abeta and increases sAPPalpha levels, which parallel elevated synaptic markers and metabolic activity in degenerating primary rat neurons. PLoS One. 2011;6(7):e21954.

137. Haas C. Strategies, development, and pitfalls of therapeutic options for Alzheimer's disease. J Alzheimers Dis. 2012; 28(2):241-281. 
138. Boche D, Zotova E, Weller RO, et al. Consequence of Abeta immunization on the vasculature of human Alzheimer's disease brain. Brain. 2008;131(Pt 12):3299-3310.

139. Engelhardt B. The blood-central nervous system barriers actively control immune cell entry into the central nervous system. Curr Pharm Des. 2008;14(16):1555-1565.

140. Lebson L, Nash K, Kamath S, et al. Trafficking CD11b-positive blood cells deliver therapeutic genes to the brain of amyloid-depositing transgenic mice. J Neurosci. 2010;30(29):9651-9658.
141. Fateh-Moghadam S, Htun P, Tomandl B, et al. Hyperresponsiveness of platelets in ischemic stroke. Thromb Haemost. 2007;97(6):974-978.

142. Stellos K, Bigalke B, Stakos D, Henkelmann N, Gawaz M Platelet-bound $\mathrm{P}$-selectin expression in patients with coronary artery disease: impact on clinical presentation and myocardial necrosis, and effect of diabetes mellitus and anti-platelet medication. J Thromb Haemost. 2010;8(1):205-207.

143. Akiyama H, McGeer PL. Brain microglia constitutively express beta-2 integrins. J Neuroimmunol. 1990;30(1):81-93.

\section{Publish your work in this journal}

Degenerative Neurological and Neuromuscular Disease is an international, peer-reviewed, open access journal focusing on research into degenerative neurological and neuromuscular disease, identification of therapeutic targets and the optimal use of preventative and integrated treatment interventions to achieve improved outcomes, enhanced survival and quality of life for the patient. The manuscript management system is completely online and includes a very quick and fair peer-review system. Visit http://www.dovepress.com/testimonials.php to read real quotes from published authors.

Submit your manuscript here: http://www.dovepress.com/degenerative-neurological-and-neuromuscular-disease-journal 